\title{
Container barge congestion and handling in large seaports: a theoretical agent-based modeling approach
}

Peter Shobayo and Edwin van Hassel ${ }^{*}$ (D)

\author{
* Correspondence: edwin. \\ vanhassel@uantwerp.be \\ Department of Transport and \\ Regional Economics, University of \\ Antwerp, Prinsstraat 13, 2000 \\ Antwerp, BE, Belgium
}

\begin{abstract}
Container Barging forms an important mode of transportation especially in large seaports with a strong inland waterway connectivity. This is because it is Cost-efficient and environmental friendly compared to the other modes of transportation. Despite the significant importance, container barge transportation is faced with several challenges and inefficiencies. One of these challenges is the large waiting time of barges in large container seaports which has negatively impacted the reliability of barge transportation. It is due to these challenges that this study seeks to examine the reasons for barge congestion and poor handling to propose possible solutions to these problems. In achieving these objectives, a quantitative methodological approach was adopted for the study in which agent-based modelling was developed to analyze the different scenarios developed in the study. An impact assessment of each of the different scenarios was conducted to identify the most suitable that would address congestion and handling issues around container barging.

The study concluded that the presence of sea vessels and the high priority given to these vessels are major causes of barge congestion in large seaports, hence the study recommends dedicated barge berthing spaces at each terminal. Appropriate smaller cranes should also be invested in, to enhance the handling of the barges.
\end{abstract}

Keywords: Barge operators, Terminal operators, Hinterland transport, Barge handling, Sea vessels, Shippers, Sea ports

\section{Introduction}

Hinterland transportation has so far become a source of enhanced competitiveness for a seaport, as it has become a source of accessibility to the port by shippers in receiving and sending their products, which has, without doubt, enhanced the performance of the port, especially in the container market. Inland waterways transportation system has been greatly influenced by containerization, and this type of shipping has developed a network of a new liner service, such as the formation of hub and spoke network which has enhanced the performance of the hub ports as well as their interconnectivity on the sea and inland (De Langen and Chouly 2004).

A rising in the increase in the volume of containers which are being handled by the seaports has made the performance and capacity of hinterland transportation an important element within the port. This is because of the significant reduction in the

(C) The Author(s). 2019 Open Access This article is distributed under the terms of the Creative Commons Attribution 4.0 International License (http://creativecommons.org/licenses/by/4.0/), which permits unrestricted use, distribution, and reproduction in any medium, provided you give appropriate credit to the original author(s) and the source, provide a link to the Creative Commons license, and indicate if changes were made. 
cost of deep-sea container transport which has led to the shift in the focus of shippers on inland operations.

An increase in the share of intermodal transportation has given the hinterland transportation a dynamic interface, as it has helped in enhancing port accessibility through the reduction of cargo from the congested roads and focusing on the transportation of these cargos by either the waterways or the railways.

Inland waterways have so far contributed to the development and performance of port activities. There has been a great emergence of container transportation through inland navigation over the years. This is because this type of transportation brings about efficient accessibility to different regions which are close to the river area such as the river Rhine, the Maas and the river Scheldt. In Fig. 1 an overview of the most important IWT network, along with the deepsea and inland container terminals is given.

More so, this mode of transportation of which the barges are commonly used offers a clean and cost-efficient method of accessing the hinterland, economies of scale and density generation as compared to transportation via trucks which have thus far enhanced the competitiveness of ports by attracting several shippers and carriers to the port.

Barge hinterland transportation has today become an important mode of transportation in large seaports with hinterland connection, because not only does it serve as an efficient and reliable mode of transport as compared with other modes, it also serves as a source of enhancing turnover in the port and reduction of congestion inland infrastructure.

As seen in Fig. 2, in total 11.3 million TEU were carried out on the north western European inland waterways in 2017. This in an increase of $37 \%$ compared to the volumes in 2007. Most of the growth is seen in the Netherlands, while both the absolute volume and the growth of container barge transport in France is much smaller. The growth in container barge transport in the Netherlands, Belgium and Germany can be directly linked to the increase of container barge hinterland transport in both

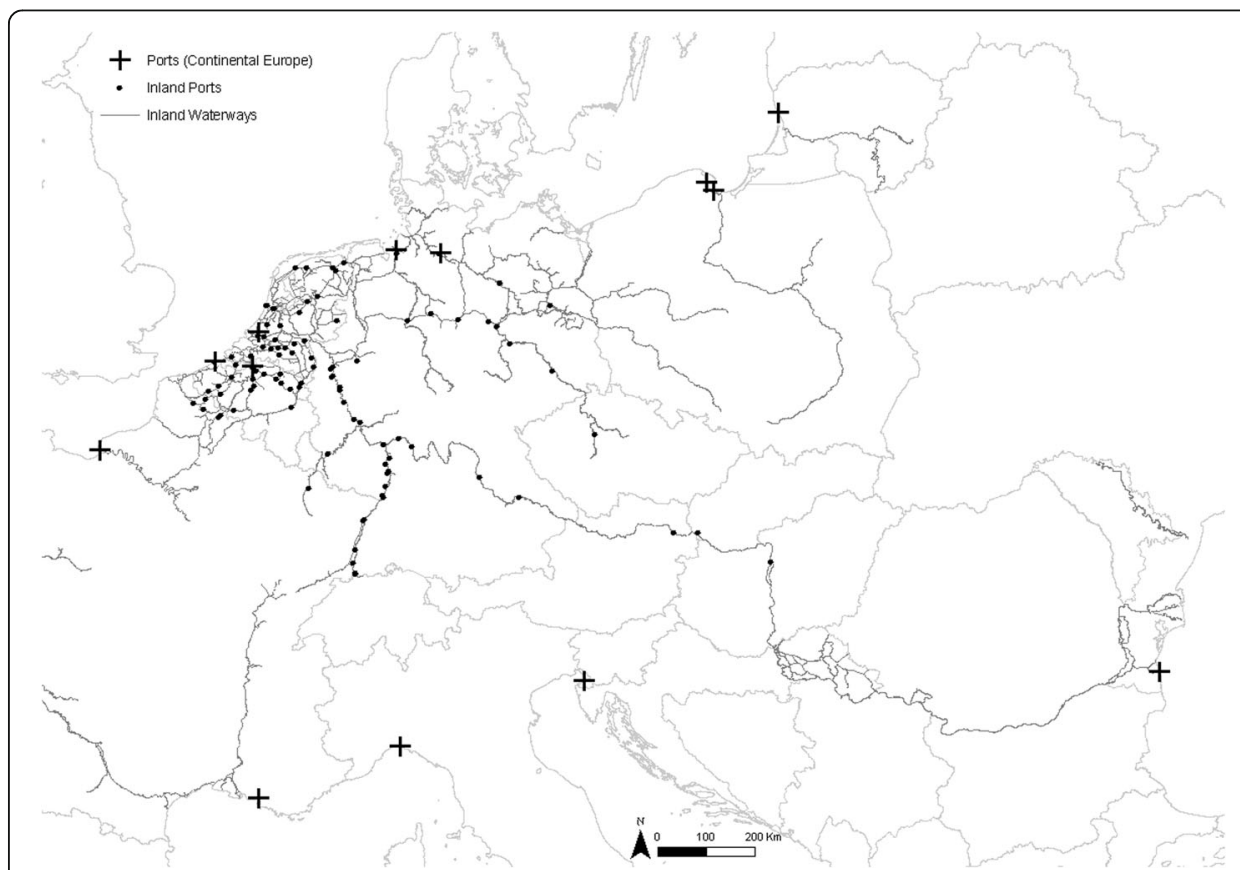

Fig. 1 Map of the most important IWT network, along with the deepsea and inland container terminals 


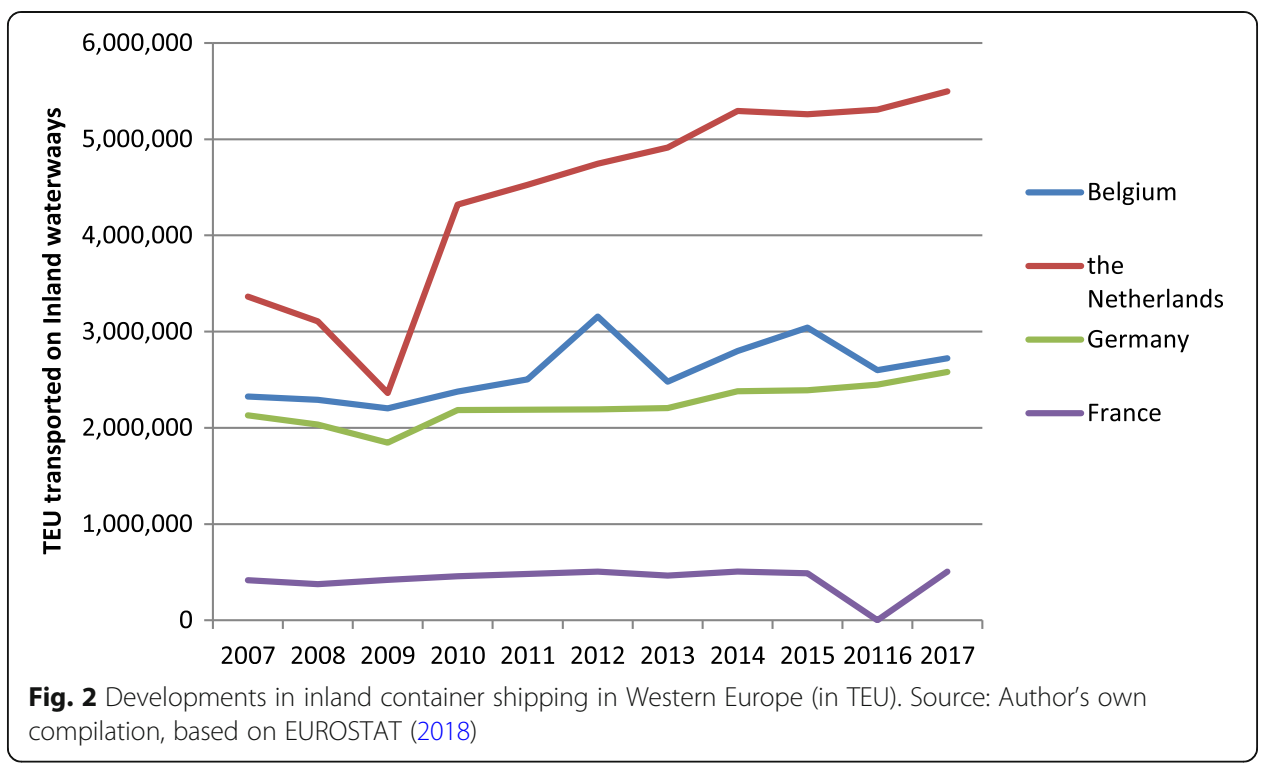

the Dutch and Belgian ports (i.e. Rotterdam and Antwerp). This shows the increasing importance of inland container barge transportation for these large seaports.

Despite the significant importance of the inland waterways to large seaports with hinterland connectivity such as the port of Antwerp and port of Rotterdam, barge transportation is still faced with several challenges which have negatively impacted the reliability of barge operations. One of the challenges is the inability to pick up and deliver containers in the shortest time possible. Some of the reasons why this challenge persists are listed below:

- Inaccurate information at the service level,

- Ineffective barge handling at deep-sea terminals,

- And most importantly, the high level of barge congestion in large seaports which has led to a high increase in waiting time. This has reduced their reliability and their level of performance in general.

In barge transportation, communication is essential between the barge operators and the terminal operators. Often time, agreements are not followed through and this leads to delay in handling at the terminal. This could disrupt the barge scheduled visit to the other terminals which in turn creates a perception of unreliability, uncertainty about its arrival time, high waiting time at the terminals and a considerably high amount of time is wasted at the port. These problems have led to huge discussions among the various actors involved in port activities with several applications, software and solutions created and proposed to improve the situation, yet there has been no lasting solution to it.

In line with these challenges, the aim of this study is to contribute to effective measures to reduce barge congestion problems in large seaports. In this sense, the study aims at reducing the waiting time of container barges at deep-sea terminals, enhancing the handling of container barges at these terminals and enhancing the reliability of container barges to improve its competitiveness with other transport modes. In achieving these objectives, the study seeks to provide answers to the identified research questions: 
i. Why is there container barge congestion in large seaports with a strong inland waterway link?

ii. How can barge congestion and waiting time be reduced at deep-sea terminals in large seaports?

In answering the research questions, the rest of the paper is structured as follows: section two focuses on the literature review, section three deals with the methodology used in the research, while section four describes the data used and section five presents the results of the research. Finally, in section six, the conclusion of the research is drawn.

\section{Literature review}

The importance of maritime transportation in international trade development over the past years cannot be overemphasized. This has led to massive growth in the world economy and has resulted in the production of huge volumes of different consumer goods (Li et al. 2017b).

According to Huang et al. (2015) container trade are expected to exceed reach 371 million TEUs by 2020. This has led to the need to develop bigger and modern ports to keep up with the envisaged growth in container shipping. Within these ports exist different deep-sea terminals which handles the large volume of containers that are being stored or transported, and there has been huge pressure on the terminals in recent time to efficiently handle the containers at a much faster rate (Petering 2011; Fan et al. 2012). Hence, coordinating and optimizing capacity and terminal resources have been a huge point of discussion over the past few years.

There has been a recent development in the inter-port competition which has led to the competition between the different transport chains (Li et al. 2017a). Ports in this sense must strategically plan how to improve hinterland connectivity. Enhanced handling of container barging could serve as a tool to improve port performance and hinterland services, which could further lead to improved attractiveness of stakeholders and shippers to shift to inland transportation (Van der Horst and De Langen 2015; Konings et al. 2013; Song and Panayides 2012). To achieve this, collaboration and cooperation must be enhanced among the different stakeholders which include barge operators, terminal operators, sea carriers and the port authorities.

The Hamburg-Le Havre range container barging is highly important to the port of Antwerp and Rotterdam, as these ports serve as the highest users of barges within this range. According to Konings (2007), the container barging in the identified ports within the Hamburg-Le Havre range can be divided into three categories:

The first category focuses on domestic trade and transportation of goods within the region. This type of container trade focuses on visiting one hinterland terminal while making several visits to different terminals in the seaport, making the barges have different calls at the terminals. Konings (2007) noted that the call size of the barges is most of the time less than 6 TEUs, and in most cases they would have to spend a lot of time waiting at the port, considering the waiting time at each of the deep-sea terminals and the movement of barges between the different terminals before eventually leaving the port.

Konings (2007) further revealed that a 150 TEU inland barge could spend just onethird of its total port time loading and unloading at the different terminals, while the remaining two-thirds can be spent waiting and sailing between the different terminals. 
The second category as identified by Konings (2007) is the container trade flow between Antwerp and Rotterdam. This trade focuses on the transportation of containers between the two ports by large ships. In this case, the ships also call at different terminals as they will have to transport containers within different locations. In this type of trade and connection, containers are shuffled between the ports to visit the different terminals.

The third category of container trade focuses on the flow from deep sea ports in Antwerp and Rotterdam with the destination focused on the Rhine regions such as Germany and Switzerland. The container trade in this category is being transported mostly by inland barges greater than 150 TEUs which would also need to call at the different terminals in the seaports and in inland terminals as well.

As seen, the three categories revealed that inland barges focused on container transportation must call at different terminals with the call size most times less than 6 TEUs. In this case, they spend a lot of time waiting and sailing to different terminals than the time they spend in loading or unloading the containers. The increased waiting and sailing time reduce their weekly departures and thus make them unable to exercise economies of density thereby increasing their cost per TEU.

Because of the loss of time at the port either through waiting or sailing to the different terminals, the economies of scale is not fully optimized which leads to an increase in the total transportation cost of the barges, thereby making barge transportation less competitive and forcing shippers to use alternative modes of transportation. Deep sea terminals, on the other hand, are affected negatively by the extremely small call size of the barges which affects their productivity and makes them less efficient in their operations. They must make use of the big cranes initially meant for the sea vessels to handle the barges which is a highly inefficient way of operating (Visser et al. 2007). This situation, therefore, leads to coordination issues from the terminals to efficiently plan the operations of both the sea vessels and container barges.

On the part of the barge operators, there have been concerns about the amount of time spent visiting the different terminals in the port, and how they have been treated at these terminals. Because of the loss of time at the port either through waiting or sailing to the different terminals, the economies of scale is not fully optimized which leads to an increase in the total transportation cost of the barges, thereby making barge transportation less competitive and forcing shippers to use alternative modes of transportation.

Deep sea terminals, on the other hand, are affected negatively by the extremely small call size of the barges which affects their productivity and makes them less efficient in their operations (Visser et al. 2007). This situation connotes lack of coordination on the part of the terminals, which can be seen in the inefficient planning of the operations of both sea vessels and container barges.

According to Van der Horst and De Langen (2015) coordination problem in inland barging exist in two folds, the first one being the long stay that exists at the port and the second deals with inadequate optimum terminal planning of sea vessels and barges. Many barges make different calls at a terminal making it nearly impossible to avoid congestion as there would be several barges coming at a certain point in time (Konings et al. 2013). Terminal operators, on the other hand, have a contractual agreement with sea vessel, giving them more priority over barges which further increases the waiting time and congestion of the barges (Nextlogic 2012). 
Van der Horst (2016) further emphasized on the coordination issue by examining the hinterland chain of inland barging and major coordination problem of barge transportation. Van der Horst (2016) reveals the contractual relationship and the hinterland chain of inland barges. There is the involvement of several public actors in the hinterland chains which include port authorities, infrastructure providers, inspection services and port authorities, while there are a few involvements of private actors who only provide transport and terminal activities.

The first issue is linked to a few call sizes from the barges and too many calls at different terminals leading to a high amount of time wasted in waiting time in the port. The researcher noted that better coordination and planning from barge operators could help reduce the number of calls. (Van der Horst 2016).

The second problem is the inadequate terminal and quay planning to better handle the barges. According to Van der Horst (2016), barge rotation average time about a decade ago was estimated at $22.5 \mathrm{~h}$ out of which $7.5 \mathrm{~h}$ were used to load and unload while the remaining $15 \mathrm{~h}$ were used in sailing and waiting to either be loaded or unloaded, and the average call size was 18 TEU per terminal (Stichting, 1998 cited in Van der Horst 2016).

The two coordination problems according to Van der Horst (2016) can be partially attributed to the lack of contractual relationship between the terminal operating companies and the barge operators. The barges are only scheduled and handled after the sea vessels have been attended to, hence passing any delay in handling the sea vessels down to the barges who have no influence on the terminal planning.

The third coordination as identified by Van der Horst (2016) focuses on the limited exchange of cargos. Exchange of cargos can bring about larger call sizes thus the use of bigger barge size which would lead to higher frequencies and fewer port calls. The problem with this, however, is that most barge owners prefer to remain independent and operate as a family business, thus preferring to operate in small quantities of cargos. This situation makes barge transportation almost unpredictable and unreliable which therefore increases cost and disrupt the supply chain process, which subsequently has affected shippers negatively.

Different models have been proposed by researchers on how barge handling can be improved at deep-sea terminals and how congestion issues can be addressed. Different applications and systems have also been developed with respect to the better handling of barges and reduction of barge congestion and waiting time at the different terminals. Table 1 was adapted from the research of Oganesian (2016) and gives an overview of the different barge related applications, in the port of Antwerp, which shows their link with other applications and stakeholder-based on a few criteria.

The table above reveals the relationship between the applications and the different stakeholders and criteria set. A positive sign shows that there is a relationship, a negative sign shows no relationship, while an empty cell reveals that information cannot be found for the link. The Barge Traffic System (BTS) for instance revealed that it targeted to everyone who is involved only in barge activities (shippers, terminal operators, barge operators, shipping company and the forwarder). It does not relate or have any link with other modes of transportation activities. More so, the BTS is linked to terminal or quay planning and depots planning and not linked with locks planning.

Different alternative models have been developed to improve barge coordination, handling and subsequently congestion in large seaports. For instance, Konings (2007) 
Table 1 Overview of the Different Port-Barge Related Applications

\begin{tabular}{|c|c|c|c|c|c|c|c|c|}
\hline \multicolumn{2}{|c|}{ Name of the application } & APCS & AFICS & BTS & CEFM & PACF & $\mathrm{CBP}$ & PBS \\
\hline \multicolumn{2}{|c|}{ Type of application } & Main platform & $\begin{array}{c}\text { Water-bound } \\
\text { traffic control } \\
\text { [data] }\end{array}$ & $\begin{array}{c}\text { Barge } \\
\text { optimization }\end{array}$ & $\begin{array}{c}\text { Barge } \\
\text { optimization }\end{array}$ & $\begin{array}{l}\text { Main platrorm } \\
\text { hinterland } \\
\text { links }\end{array}$ & $\begin{array}{l}\text { Hinterlandt } \\
\text { bundling }\end{array}$ & $\begin{array}{l}\text { Barge } \\
\text { bundling }\end{array}$ \\
\hline \multicolumn{2}{|c|}{$\begin{array}{c}\text { Open/Closed (everyone } \\
\text { can access it) }\end{array}$} & $\begin{array}{c}\text { for registered } \\
\text { users }\end{array}$ & - & + & - & + & + & \\
\hline \multirow{3}{*}{$\begin{array}{l}\text { Provides } \\
\text { information } \\
\text { about: }\end{array}$} & $\begin{array}{c}\text { Port of } \\
\text { Antwerp } \\
\end{array}$ & + & + & + & + & + & + & + \\
\hline & $\begin{array}{l}\text { Inland } \\
\text { terminals }\end{array}$ & - & + & & - & - & + & + \\
\hline & Overall & - & + & - & - & - & + & - \\
\hline \multicolumn{2}{|c|}{ Accuracy } & + & & & + & + & & + \\
\hline \multicolumn{2}{|c|}{ Time scheduling } & + & - & + & + & + & - & Finedr \\
\hline \multirow{4}{*}{$\begin{array}{l}\text { Uniting } \\
\text { different } \\
\text { transport } \\
\text { modes }\end{array}$} & Rail & - & - & - & - & & + & + \\
\hline & Barge & + & + & + & + & + & + & + \\
\hline & Truck & + & - & - & - & & + & - \\
\hline & $\begin{array}{l}\text { Deepsea } \\
\text { vessels }\end{array}$ & + & + & - & & & + & - \\
\hline \multirow{6}{*}{$\begin{array}{c}\text { For whom } \\
\text { application } \\
\text { was } \\
\text { developed } \\
\text { (Target } \\
\text { Group) }\end{array}$} & $\begin{array}{c}\text { Port } \\
\text { authority }\end{array}$ & + & + & - & + & + & + & + \\
\hline & Shippers & + & & + & + & + & + & + \\
\hline & $\begin{array}{l}\text { Terminal } \\
\text { operator }\end{array}$ & + & & + & + & + & + & + \\
\hline & $\begin{array}{c}\text { Barge } \\
\text { operator }\end{array}$ & + & & + & + & + & + & + \\
\hline & $\begin{array}{l}\text { Shipping } \\
\text { company } \\
\text { (carrier) }\end{array}$ & + & & + & + & + & + & + \\
\hline & Forwarder & + & - & + & + & + & + & + \\
\hline \multirow{3}{*}{$\begin{array}{l}\text { Planning in } \\
\text { the port }\end{array}$} & Locks & + & + & & - & & & - \\
\hline & $\begin{array}{c}\text { Terminals/Q } \\
\text { uays }\end{array}$ & + & + & + & + & & & - \\
\hline & Depots & & & + & - & & + & + \\
\hline \multicolumn{2}{|c|}{$\begin{array}{c}\text { Cargo flow bundling } \\
\text { (accumulation of } \\
\text { container volumes } \\
\text { provision) }\end{array}$} & - & - & - & - & - & + & - \\
\hline
\end{tabular}

carried out a research on the opportunities to improve container barge handling in the port of Rotterdam. The researcher developed two collection and distribution models by which barge services could be reorganized. The first model is a container exchange point service model where all the hinterland vessels call at one terminal which serves as a container exchange point, while the second model is the multi-hub terminal service model where hinterland vessels also call directly to large container terminals, however the collection and distribution of small container batches are carried out locally.

The researcher concluded that barge operators would enhance productivity if they could reduce the number of terminals they visit at the port, and this reduction could be achieved by avoiding terminals with small batches, hence these small batches should be reorganized through specialized transport services for collecting and distributing the batches.

Douma et al. (2009) examined the efficient protocol in planning container barge rotations along terminals in the port of Rotterdam with a view to reducing the waiting time of the barges. They developed a multi-agent-based control which tries to integrate barge rotation and terminal capacity with the view to understanding the functionalities of the system. 
Fu et al. (2010) conducted a research on the rationalization of port resources to enhance better handling of barge services in Hong Kong. They conducted a simulation model to analyse three strategies and concluded that the centralization strategy whereby containers are consolidated offers the best strategy for all the parties involved, as it would reduce congestion at the port, reduce dwell time of cargoes and reduce the waiting time of barges at the port.

Douma et al. (2011a, 2011b) examined the alignment of barge and terminal operations using service time profile. In doing this they designed a multi-agent model. They discovered in their research that opening time restriction and services to sea-going vessels significantly affect the visits of barges and the pattern of their arrivals at the terminals. It was discovered that barges tend to avoid going to terminals that have restricted opening times towards the end of the day because of the risk of staying overnight at the terminal.

Douma et al. (2011a, 2011b) examined the degree of terminal cooperativeness on the efficiency of the barge handling process. They developed a multi-agent system where they used the barge operators and the terminal operators as the decision-making actors. Their study focused on the degree of responsiveness among terminal operators in which they focus on the extent to which a terminal provides insight to how occupied it is for the day, and the extent to which a terminal is willing to keep up with an appointment. It was discovered that the way terminals deal with barges go a long way in influencing their performance. Hence, barges will produce a greater performance when they do not book an appointment with the terminals but rather are served on a first come first serve basis.

Caris et al. (2011) examined the network analysis of container barge transport through a simulation model. The researchers simulated and compared four alternative scenarios. The first was to develop a hub on the right river bank where the hub creates a shuttle service to collect and distribute containers to sea terminals, and barges from inland terminals only must visit the hub to pick up and deliver their packages.

The second scenario was the creation of a hub on the left river bank which follows the same services as the first scenario but just situated on the left bank of the river. The third scenario was the creation of a first multi-hub where there is hub in the cluster of sea terminals both on the left and right riverbank, while the fourth scenario was the creation of a multi-hub 2 where hubs are also created in both side of the river bank as in the third scenario, but inland barges only have to visit one hub where they do not have to pass through a lock in the port area.

The scenarios were analysed using the discrete event simulation model. The findings revealed that the fourth scenario leads to a significant reduction in the turnaround time and leads to the optimal situation for both the terminal and barge operator.

Van der Horst and Kuipers (2013) examined the multidisciplinary analysis behind the coordination problems in container barging in the port of Rotterdam. The study adopted a case study approach and focused on inland barging activities at the port of Rotterdam. The result of the case study approach revealed that even though there are many interdependent actors that have different arrangements in ways on how the container barging problems can be improved, these actors do not provide a sense of urgency on the need to improve the situation.

Al Enezy et al. (2017) developed a cost calculation model for inland navigation where they calculated the specific cost for barge transportation, including the cost of waiting time, congestion cost, external costs, variable costs and fixed costs. The researchers 
developed a generic cost calculation model to address the shortcoming of the existing models and application. Findings revealed that utilizing models for inland navigation should be dependent on the input factors of a specific company, this is due to the differences in ship types, mode of operation and the contract type.

Li et al. (2017a) examined the closed-loop coordination of inland vessels operations in large seaports by using a hybrid logic-based benders decomposition. The aim of the research was to address two of the coordination problems persistent in waterborne transport in large seaports. The first coordination problem involves the high waiting time of inland barges at the port, while the second coordination problem focuses on the inadequate terminal and crane planning for inland barging with respect to the sailing schedules. The researchers simulated a coordination model using a logic-based bender and large neighbourhood search. The result of the simulation reveals that the model could serve as a solution for a round trip time of the inland barging as compared to the centralised approach. The result further revealed that the coordination approach could lead to a $10 \%-15 \%$ reduction of the time spent in the port for inland barges while reducing the waiting time at the terminals by $24 \%-35 \%$.

$\mathrm{Li}$ et al. (2017b) further examined the planning of inland vessel operations in large seaports by using a two-phase approach. They developed mixed-integer programming with a constraint programming to develop rotation plans for the inland vessels. The first phase approach was addressed using the mixed integer programming, while the second phase approach was addressed using the constraint programming. The result of the simulation reveals that the proposed two-phase approaches could be beneficial to both vessel operators and terminal operators.

In as much as there are various applications to reduce barge congestion issues, the problem persists. Various studies have been conducted to discover the optimum solution to reduce barge congestion in large seaports, these studies have however failed to take a closer look at the main identified cause of congestion which is the low priority to barges due to non-contractual relationship with the barge operators and tried to optimize the barge priority issue to determine if this approach would lead to a reduction in congestion and further improve barge handling and the barge situation in general.

It is to this effect that the present study tries to address the research gap by developing an agent-based model to address the priority issues of barges. In doing this, the study proposed three scenarios and identify the optimum scenario with respect to barge congestion and handling in large seaports with hinterland connection. In order to assess these different scenarios an agent based model is built to.

\section{Methodology}

A quantitative methodological approach is adopted for this study to provide answers to the research questions earlier identified. In achieving this, a two-step approach is developed. These steps are:

i. Development of scenarios for possible solutions to solve the barge congestions problem (based on literature review).

ii. Development of an agent-based modelling to analyze the different scenarios earlier developed. 
For the development of the three cases, two interrelated systems (Barge traffic system and barge handling at terminals in a seaport) are considered. The three scenarios were developed based on the insights developed in the literature part of this paper. In Fig. 3 the schematic overview of the three developed scenarios is given.

The first scenario examines the situation of barge congestion and handling at the terminals when each terminal operator takes an independent decision on its capacity and availability to book plan time slots for the barge operators. This is the base scenario where the sea vessels have high priority while the container barges have very low priority. Hence, vessels are ensured to be handled before the handling of the barges, thus the barges must wait until the vessels are handled.

Scenario two examines the container barge congestion, handling and queue build if barges have dedicated terminal space, quay and cranes without the interference of the sea vessels. In this case, the vessels (sea vessels and container barges) have their respective handling terminal berthing space.

Scenario three examines the container barge congestion, buildup and handling in the case where there is integrated planning and the barges have a significant share of priority even though they share terminal space and resources with the sea vessels. In this case, the terminal operators try to handle the barges as soon as possible and if they are

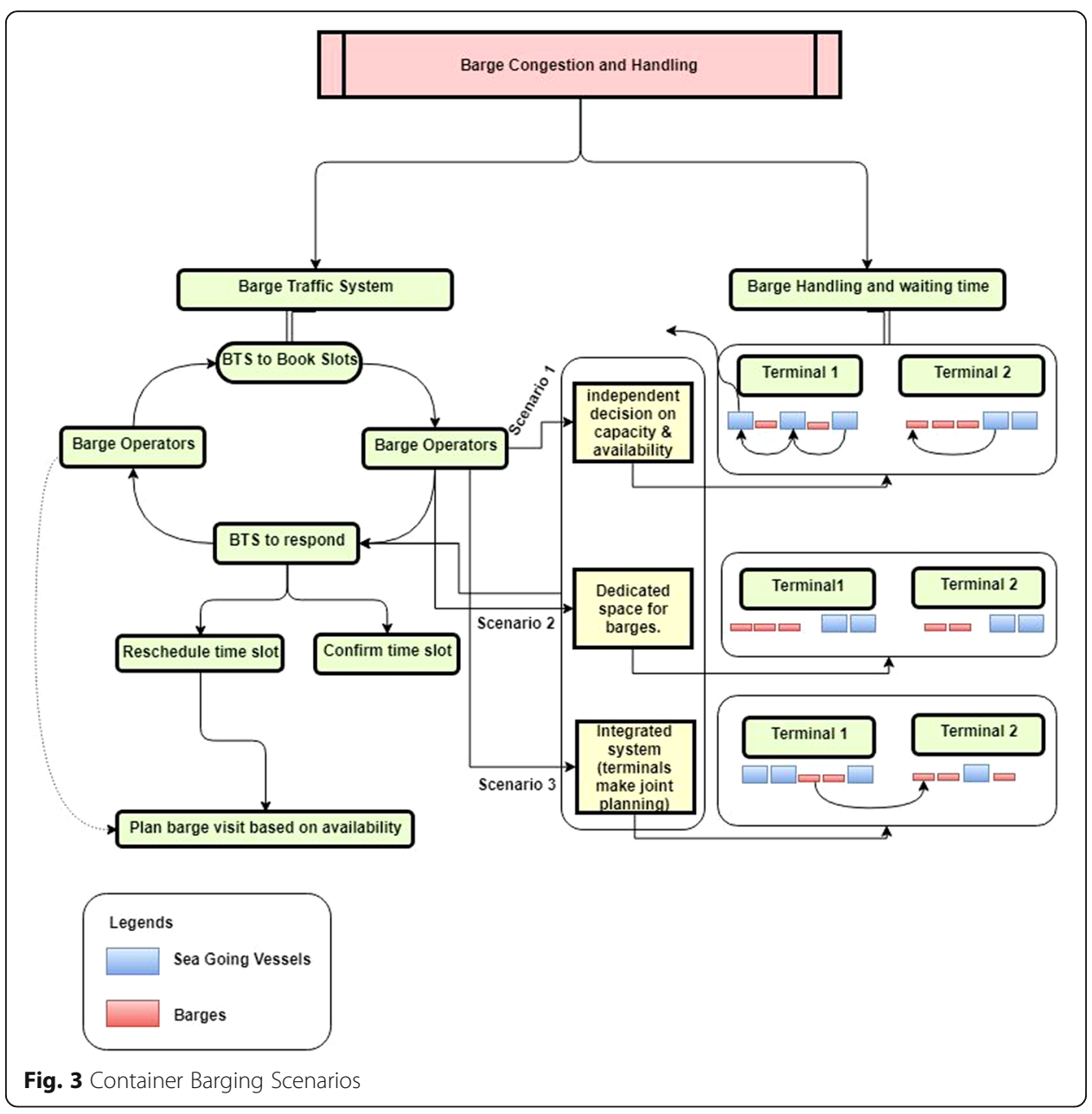


unable to do so, they tend to move them to a free terminal now based on the planning and schedule of the terminal.

In line with the identified scenarios, the Agent-Based Model (ABM) approach which will be adopted to examine the different scenarios and analysed using NetLogo Wilensky, U. (1999). Agent-Based Modeling (ABM) is a technique which simulates the interactions of a set of agents in a behaviour environment (Reis 2014). This technique takes into consideration a system which consists of the interaction of agents within an environment that supports the existence of the agents (Bonabeau 2002). The conceptual outlook of an agent is very important in ABM.

Different models and techniques have been adopted in examining barge handling and congestion in large seaports. For instance, Konings (2007) in their study developed a container exchange point service model to improve barge handling. Douma, Schutten and Schuur (2009) developed a multi-agent-based control to integrate barge rotation and terminal capacity in the ports. Fu, Liu and Xu meanwhile developed a simulation model to determine how to enhance barge handling.

Douma et al. (2011a, 2011b) developed an experimental system to determine the level of cooperativeness of terminal operators in efficiently handling barges. Van der Horst and Kuipers (2013) meanwhile used a case study approach in examining barge coordination and congestion problems. Li et al. (2017a, 2017b) developed a simulated coordination model to examine the coordination of inland vessels in large seaports. The researchers further developed a mixed integer programming to determine the efficient planning of inland vessels.

As much as the various models are targeted to enhancing the poor handling of barges, they have so far not addressed the main cause of poor handling of these barges which thereby creates a high level of congestion. More so, the researchers have so far not integrated the main cause of the poor handling and congestion into their models. It is to this effect that the present study tries to integrate the main cause of barge congestion with the reaction of barges to different scenarios and priority level.

In achieving this, agent-based modelling is seen as an ideal model to model to combine these two approaches and draw some conclusion from their reactions. This makes the agent-based model unique for this study as it examines the behaviour of barges and how they respond to congestion based on different priority levels determined in the model. Hence, the model gives an important insight into the reactions of the barges on different scenarios and priority levels.

An agent can be classified as an independent entity that has specific objectives, display autonomous behaviour and is capable of sensing and communicating. Successful utilization of $\mathrm{ABM}$ is dependent on three major components which are: agents, interaction and environment. An agent could have complete or incomplete information of its surroundings and may be able to influence others around the environment.

The interaction between agents focuses on how the agents communicate with each other to get information and act based on the information gathered, while the environment is a physical location that allows for the agents' interaction (North and Macal 2007). The overall behaviour and properties of a system are related to the dynamic interactions and behaviours of the agents in the system, which is the result of whether an agent is pursuing a certain objective or reacting to a certain action. Thus, ABM follows a bottom-up approach to understanding the real-world situation. 
The $\mathrm{ABM}$ approach has a number of advantages over the traditional modelling approach, such as the ability of ABM to generate an unlimited number of agents, more so, the ABM approach gives the chance to model and study the interaction of each of the agent, finally, the ABM approach is a dynamic approach where the system and the agents have the ability to store and recall events (Reis 2010).

There have been a few studies that have used ABM principles to provide solutions to transport related studies. For instance, Fischer et al. (1995) conducted research to examine if $\mathrm{ABM}$ principles were useful in understanding negotiation and cooperation dynamics in the road freight transport market. They concluded that the ABM approach was a useful technique in understanding and solving scheduling problem complexity.

Baindur and Viegas (2011) conducted an ABM for supporting public policy designs and promoting intermodal short sea transport. They conducted scenario analysis with the $\mathrm{ABM}$ and concluded that a fixed regulatory layer that was held constant over the period of the experiment was determined by each of the public policy. In this regard, the ABM analysis will help to answer the identified research questions.

The objectives of the model is to provide insight into the problem of barge congestion and to examine the different scenarios which could tackle the problem of barge congestion in large seaports. Hence, the in-depth technical details on the complex operations of barges, sea vessels and terminals are not considered in the model. The developed model is intended to set a foundation where future models can be built on, which will include more sophisticated algorithms.

Thus, in providing answers to the research questions earlier identified an agent based model has been developed. The model tries to simplify the interaction that exists between the different agents (terminals, sea vessels and barges). In Fig. 4 the main outline of this model is shown.

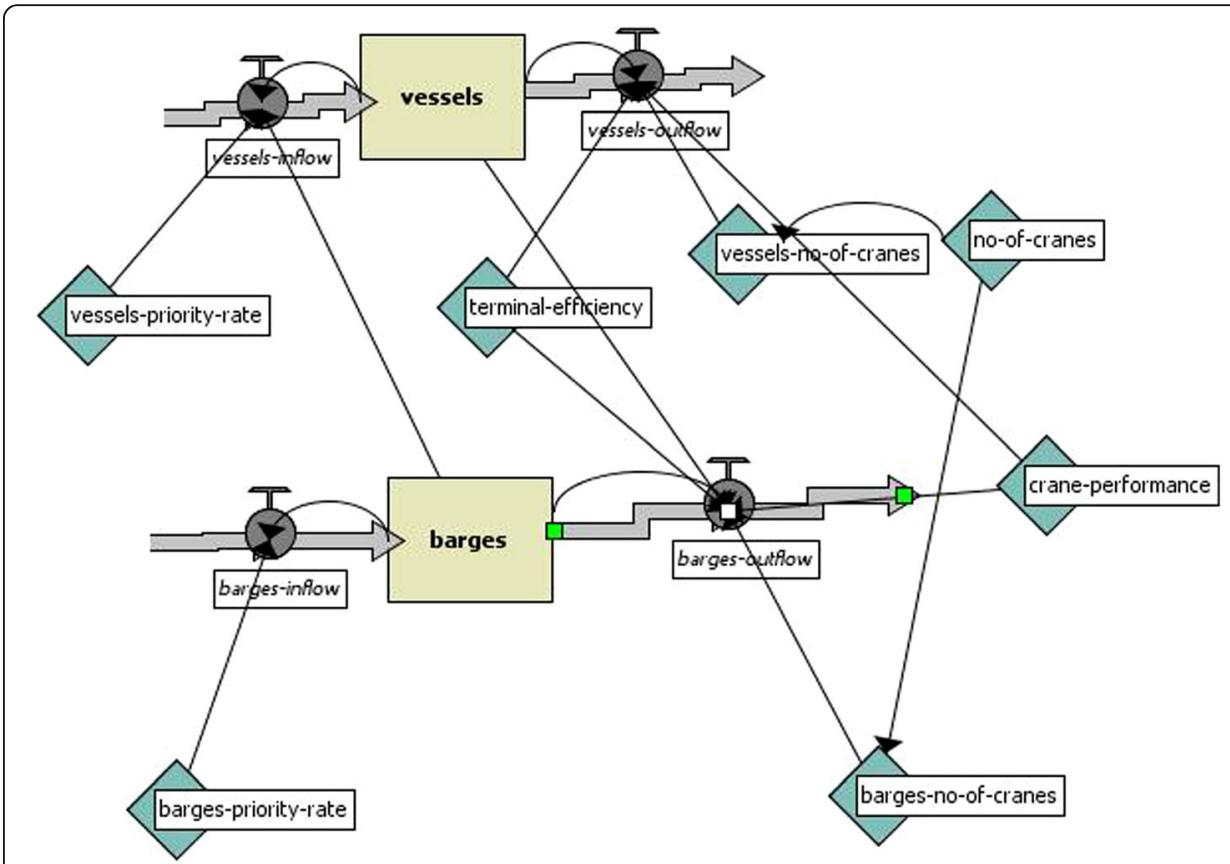

Fig. 4 Main outline of the Agent-Based Model 
The figure explains the relationship between the agents (barges, vessels and terminals). The vessel inflow is the rate at which new vessels enter the system, and this is dependent on the vessel priority rate, the number of vessels that are already in the system and the number of barges that are already in the system.

The number of vessels and barges already in the system are set by vessel and barge slider and in this case, is set at 3 for the vessels and for the barges. These parameters are however calibrated in line with the different cases. The vessels outflow, on the other hand, is dependent on several factors such as the number of vessels already in the system, the terminal efficiency, the number of cranes allocated to the vessels, as well as the crane performance. All the parameters are calibrated accordingly in line with the different cases and sensitivity analysis.

Meanwhile, the barges inflow meanwhile is dependent on the barges priority rate as well as the number of barges that are already in the system. The barges outflow, on the other hand, is dependent on the number of barges already in the system, the number of vessels already in the system, the terminal efficiency, the number of cranes allocated for the barges as well as the crane performance.

Terminal operations meanwhile have to do with the total number of cranes that are available at the terminal, as well as how the cranes are allocated to the vessels and the barges, the crane performance and finally, terminal efficiency.

A model is a simple representation of reality, hence this model only captures a part of the operational observation of the terminals which deals with congestion and handling, by giving more priority and allocating most of their resources to the vessels. This is the essence of this study, as this has been discovered to be the main cause of congestion and poor handling of barges in large seaports. Thus, the technical operational activities of the terminals such as their planning, how the cranes are allocated, how many gangs are planned for each vessels are not captured in the model.

From the agent-based model, the inflow of vessels is determined by the priority rate set for the vessels controlled by the vessels priority rate slider between 0.1 and 1.0. Priority rate is explained to be the percentage that the vessel would be handled as soon as possible. Hence, 0.1 implies that there is a $10 \%$ chance that it would be handled as soon as possible, while 1.0 implies $100 \%$ chance of being handled as soon as possible.

The inflow of barges, however, is determined by the priority rate for barges which is set by barges priority rate slider. The vessels and barges variables are the main variables examined in the model which are initially set by the vessel's slider and the barges slider respectively while monitoring the increase and decrease of the initial numbers at each period.

Vessels outflow is determined by terminal efficiency, the number of cranes allocated to vessels and crane performance. Terminal efficiency is set by a terminal efficiency slider which ranges from 0.1 to 1.0 , where 0.1 implies $10 \%$ efficiency which means the terminal is less efficient and 1.0 implies $100 \%$ efficiency which means high efficiency. The number of cranes allocated to vessels is determined by the vessels priority rate and the total number of available cranes at the terminal.

The available cranes are set by the number of cranes slider in the model, thus, the allocated cranes assigned to deep-sea vessels is the vessel priority rate multiplied by the number of cranes slider set in the model. Therefore, the higher the priority rate, the higher the number of cranes that will be allocated to the deep-sea vessels. The crane performance depends on the number of cranes allocated to the barges 
and the vessels. In this case, more cranes are allocated to the vessels, hence the vessels are handled as fast as possible.

The total number of cranes is set by crane slider ranging between 0 and 100. Crane performance meanwhile is set by a crane performance slider ranging between the values 0.1 to 1.0 , where 0.1 implies $10 \%$ performance level representing poor performance and 1.0 implies $100 \%$ performance representing high performance.

The outflow of barges, on the other hand, is determined by the number of vessels, crane performance, terminal efficiency and the number of cranes allocated to barges. The crane performance, terminal efficiency and number of cranes remain the same as the situation with the vessels above. However, the number of cranes allocated to barges is determined by the total number of cranes and the barges priority rate.

In summarizing the model, the number of barges accepted in the terminal at a certain period is a function of the priority rate given to the barges and the inflow of sea-vessels visiting the terminals at a certain period (which is a function of the priority rate of vessels and number of vessels available). The outflow rate of barges meanwhile rate is a function of the number of barges in the system, the number of vessels that is handled, the number of cranes reserved for barges and terminal efficiency.

\section{Data for ABM}

The data used to analyse the scenarios was generated from the output of the agentbased model. The model itself was developed based on the information derived from barge operators (ibarge) and terminal operators (MPET) on barge activities in the port of Antwerp. Hence, the model was developed with the input from the information (information related to terminal efficiency, crane performance, number of barges and sea vessels that is being handled in a month and number of cranes in the terminal) received from these stakeholders.

Thus it can be said that there is high level of confidence in the model which has gone through requirement validation (a reflection of real world scenario), theory validation (the model contains valid assumptions and is in line with the operational practices of barge handling, communication and information sharing) and process validation (there is a clear and meaningful interaction among the agents that correspond to real-world process). Thus, it can be said that the data generated from the model to analyse the different scenarios have a high degree of validity. The overview of these validated inputs is given in Table 2.

With respect to the barges, the assumptions were based on discussions with terminal and barge operators to be of an average size of $110 \mathrm{~m}$ long and $11.4 \mathrm{~m}$ width with a draft of $3 \mathrm{~m}$, a capacity of 200 TEUs and an average call size of 20 TEUs. Sea vessels on their part were assumed to be an average of $360 \mathrm{~m}$ long, $53.6 \mathrm{~m}$ width, 16,000 TEUs capacity and an average call size of 2000 TEUs. These assumptions are for the ABM analysis and it is based on inputs from discussions with terminal operators $\left(\mathrm{MPET}^{1}\right)$ on the average size of vessels that called at their terminals in 2018.

As explained, three cases are analyzed and each of the cases has different situations where the parameters were adjusted to examine the resultant effect of barge congestion on each of the parameters. Table 3 identifies the three cases, the different situations in each of the cases and the parameters set for each of the situations. 
Table 2 Overview of the different inputs in the ABM

\begin{tabular}{|l|l|}
\hline S/N & General Inputs \\
\hline 1 & All terminal operators and barge operators use the BTS. \\
\hline 2 & $\begin{array}{l}\text { Deep sea vessels have high priority (once a sea going vessel is in a terminal, all } \\
\text { terminal resources are channeled towards the vessels because of the contractual } \\
\text { relationship between them and the terminal operators). }\end{array}$ \\
\hline 3 & $\begin{array}{l}\text { The barge operators can only act and plan their barges based on the vessels } \\
\text { schedules and handling. }\end{array}$ \\
\hline 4 & All inland barges have the same size. \\
\hline 5 & The container inland barges have the same average call size of 20 TEUs \\
\hline 7 & $\begin{array}{l}\text { The crane performance is assumed to do } 35 \text { moves per hour both for the barges } \\
\text { and the sea vessels. }\end{array}$ \\
\hline 7 & $\begin{array}{l}\text { The number of cranes is allocated to the terminals according to their priority } \\
\text { level. In this sense, sea vessels have greater number of cranes handling them. }\end{array}$ \\
\hline
\end{tabular}

Table $\mathbf{3}$ The three cases and their respective parameters (case 1 is the base scenario)

\begin{tabular}{|c|c|c|c|}
\hline$s / n$ & Case & Parameters & Values \\
\hline \multirow{7}{*}{1} & \multirow{7}{*}{$\begin{array}{l}\text { Case 1: Independent decision } \\
\text { on capacity and availability }\end{array}$} & Vessel priority rate. & 0.9 of 1.0 \\
\hline & & Barges priority rate. & 0.1 of 1.0 \\
\hline & & Number of barges at time & 10 \\
\hline & & $\begin{array}{l}\text { Number of vessels at } \\
\text { time zero. }\end{array}$ & 3 \\
\hline & & Technical efficiency. & $80 \%$ \\
\hline & & Crane performance. & 35 moves per hour \\
\hline & & Number of cranes. & 20 \\
\hline \multirow{7}{*}{2} & \multirow{7}{*}{$\begin{array}{l}\text { Case 2: Dedicated Space and } \\
\text { Infrastructure for Barges }\end{array}$} & Vessels priority rate. & 0 of 1.0 \\
\hline & & Barge priority rate. & 0.5 of 1.0 \\
\hline & & $\begin{array}{l}\text { Number of barges at time } \\
\text { zero. }\end{array}$ & 10 \\
\hline & & $\begin{array}{l}\text { Number of vessels at } \\
\text { time zero. }\end{array}$ & 0 \\
\hline & & Terminal efficiency. & $80 \%$ \\
\hline & & Crane performance. & 35 moves per hour \\
\hline & & Number of cranes & 2 \\
\hline \multirow{7}{*}{3} & \multirow{7}{*}{$\begin{array}{l}\text { Case 3: Integrated Planning } \\
\text { and Higher Priority for Barges }\end{array}$} & Vessel priority rate. & 0.9 of 1.0 \\
\hline & & Barge priority rate. & 0.5 of 1.0 \\
\hline & & $\begin{array}{l}\text { Number of barges at time } \\
\text { zero }\end{array}$ & 10 \\
\hline & & $\begin{array}{l}\text { Number of vessels at } \\
\text { time zero }\end{array}$ & 3 \\
\hline & & Terminal efficiency & $80 \%$ \\
\hline & & Crane performance & 35 moves per hour \\
\hline & & Number of cranes & 20 \\
\hline
\end{tabular}




\section{Case one - independent decision on capacity and availability}

This is the base case of the current situation at the terminals. In this situation, the study assumes that the deep-sea terminals make independent decisions on their capacity and availability. This is the current situation at the terminals. They give priority to sea-going vessels due to the contractual relationship that they have with them, which is one of the problems of barges and barge operator.

Hence in this case, the vessel priority rate was set to 0.9 (90\% probability that it would be handled as soon as possible) which represents high priority for the vessels, while the barges priority rate was set to 0.1 (10\% probability that they would be handled as soon as possible) which represent low priority for the barges. The initial number of barges at time step zero was set at 10 barges while the number of vessels to set to 3 which means there are 10 barges and 3 sea vessels waiting to be handled respectively at time step zero. The terminal efficiency is assumed to be 0.8 ( $80 \%$ efficiency performance) which is highly efficient, crane performance is assumed to do 35 moves per hour, while the number of cranes is set at 20 .

\section{Case two - dedicated space and infrastructure for barges}

This case examines what the situation of barges would look like if the barges have dedicated space with only two cranes to handle the barges. In this case, the initial number of barges in the system at time step zero is 10, the priority rate increased to 0.5 (50\% of being handled as soon as possible) This value was selected as a worst-case probability to take care of unforeseen circumstances such as gang unavailability, delay in time slots or schedules and some other extreme external factors. There are no vessels and no vessel priority rate, while the terminal efficiency and crane performance remain constant as with the first case.

\section{Case three - integrated planning and higher priority for barges}

This case examines what the situation would be if the terminal operators make joint planning and give a higher priority to the barges while also maintaining the high priority of the seagoing vessels. In this scenario, the priority rate of the barges is increased to 0.5 (50\% chance of being handled as soon as possible) while the sea-vessels still maintained the initial 0.9 ( $90 \%$ chance of being handled as soon as possible) that was set.

The number of cranes remained 20 and the initial number of barges at the time set 0 remained 10, while that of sea-vessels remained 3 . The only difference between this case and the first case is the significant increase in the priority rate of barges, as the terminal operators are assumed to give them more importance, which means they are handled as soon as possible and there is joint and integrated planning by all stakeholders to ensure that they are attended to as soon as possible.

\section{Results}

The results of the three cases are presented in this section, afterwards, a sensitivity analysis was conducted to adjust some parameters in each of the scenarios and see what the outcomes are if some parameters are changed. All model runs last for 50,000 ticks ${ }^{2}$ on NetLogo to examine the flow of barge congestion over time. This can take a couple of hours depending on the speed set for the model to run and the computational power of the computer. Figure 5 reveals that the number of barges waiting at a different time in case 1. 


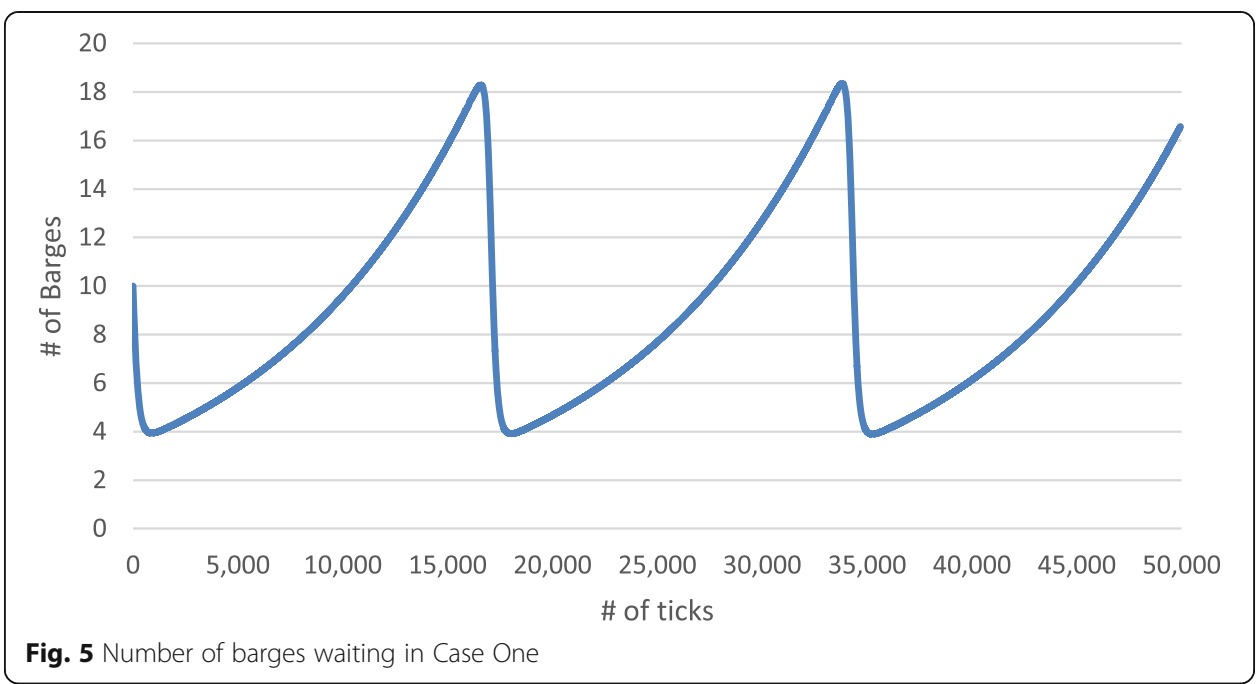

At time step zero of 10 barges, hence the barges are handled at a high rate. However, as the number of barges reduces, the handling rate also drops due to the focus of terminal operators on sea vessels which therefore affect the rate at which the barges are being handled and leaves the system.

When the number of barges eventually drops to four, no barges are handled at that period and full attention is focused on the vessels, leading to potential queue and waiting time of the barges. The reason for four barges is because the terminal operators must distribute the available cranes across the sea vessels waiting to be handled, hence there are no more cranes handling the barges. The barges remain in the system while more barges join to be handled, meanwhile, none of the barges is leaving the system.

This then led to an eventual queue of up to 18 barges waiting to be handled and leave the system. Once the number of barges increases to 18 , attention is once again focused on the barges. However, as the number of barges drops again, the outflow rate drops accordingly suggesting that focus is being shifted away from the barges.

This situation continues throughout the time steps, and as can be seen, the barges can increase to 18 from an initial value of 10 , while there will always be at least 4 barges waiting to be handled at a certain tick. An observation in the graph suggests that the container barges are only handled when there are a buildup and an increased number of barges waiting to be handled. As soon as this number drops to a certain level, the focus is shifted away from them.

Figure 6 explains the case two of dedicated space and infrastructure for barges. The graph below reveals that using a dedicated space and investing in only two cranes for the barges with a priority rate of 0.5 , there is an increase in the barges from 10 at time step zero to 14 throughout the time steps. This implies that the number of barges increases, the rate at which they are handled will also increase which would then attract more barges in the system. The attractiveness of more barges is not however supported with the increase of infrastructures contributing to the increase in the number of barges.

Figure 7 explains the third case where there is integrated planning and higher priority for barges. As seen in the graph, a significant increase of barges leads to a similar situation as it was the case in the first case, and even in this case, the number of barges increased more as compared to the first case. This implies that increasing barge priority 


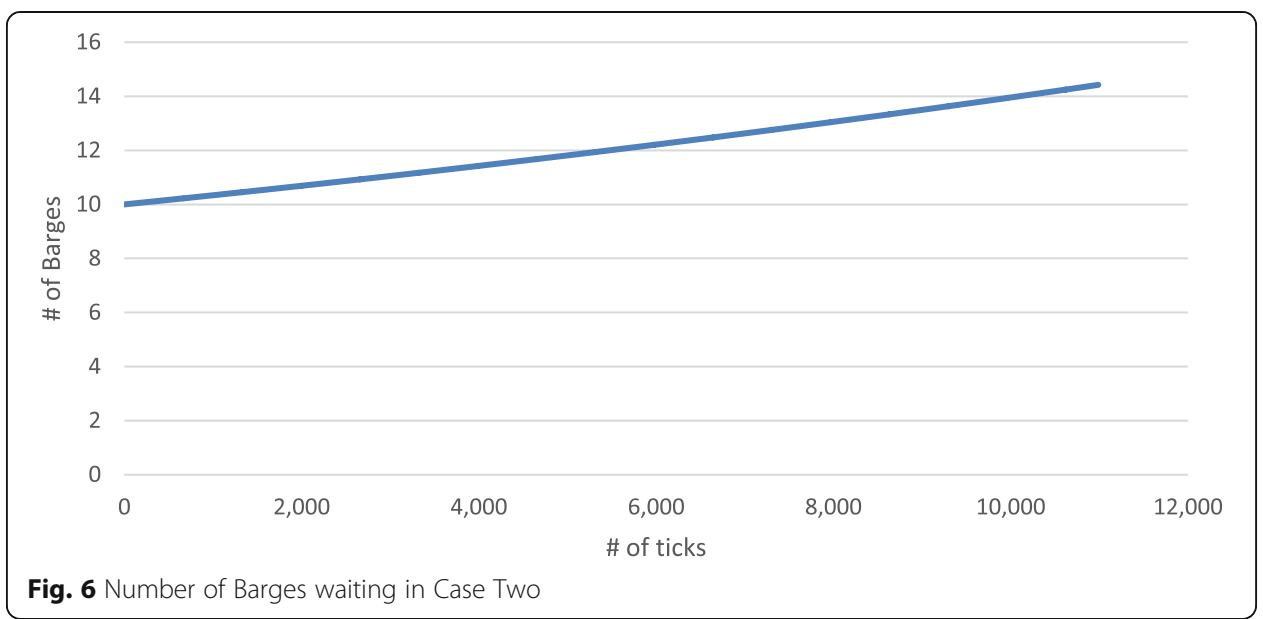

when there is still the presence of sea-going vessels would only lead to a further increase in barge congestion as more barges would be attracted to enter the system and thus would have to eventually wait to be handled because of the presence of the sea-vessels.

Because this case leads to a similar situation as with the first case, the sensitivity analysis is not conducted in the next section as it produces a similar result as with the first case scenario.

\section{Sensitivity analyses}

Having conducted the preliminary analysis of the three cases. Sensitivity analyses were further conducted to examine how barge congestion would be affected by the changes in some of the parameters earlier identified in each of the cases. The changes in these parameters are identified in Table 4.

Figure 8 compares the sensitivity analysis in the changes of parameters for case one. In this case, sensitivity analysis one for case one examines what would happen if only the number of cranes is increased from 20 to 30 while the other parameters in case one remains constant. Increasing the cranes without increasing priority rate of barges

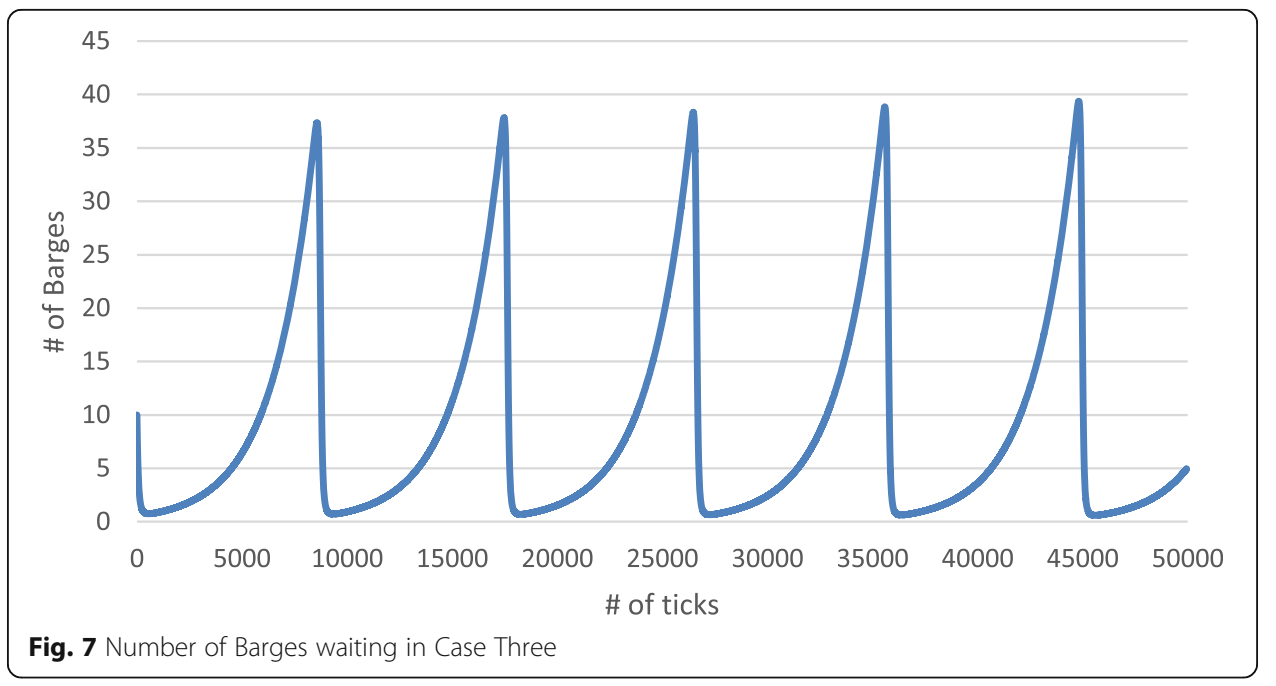


Table 4 Parameters for Sensitivity Analyses

\begin{tabular}{|c|c|c|c|}
\hline$s / n$ & Case & Parameters & Values \\
\hline \multirow{7}{*}{1} & \multirow{7}{*}{$\begin{array}{l}\text { Case 1: Independent } \\
\text { decision on capacity and } \\
\text { availability }\end{array}$} & Vessel priority rate. & 0.9 of 1.0 \\
\hline & & Barges priority rate. & 0.1 of 1.0 \\
\hline & & Number of barges at time zero. & 10 \\
\hline & & Number of vessels at time zero. & 3 \\
\hline & & Technical efficiency. & 0.8 of 10 \\
\hline & & Crane performance. & 35 moves per hour \\
\hline & & Number of cranes. & 30 \\
\hline \multirow{7}{*}{2} & \multirow{7}{*}{$\begin{array}{l}\text { Case 1: Independent } \\
\text { decision on capacity and } \\
\text { availability }\end{array}$} & Vessel priority rate. & 0.8 of 1.0 \\
\hline & & Barges priority rate. & 0.2 of 1.0 \\
\hline & & Number of barges at time zero. & 10 \\
\hline & & Number of vessels at time zero. & 3 \\
\hline & & Technical efficiency. & 0.8 of 10 \\
\hline & & Crane performance. & 35 moves per hour \\
\hline & & Number of cranes. & 20 \\
\hline \multirow{7}{*}{3} & \multirow{7}{*}{$\begin{array}{l}\text { Case 2: Dedicated Space } \\
\text { and Infrastructure for } \\
\text { Barges }\end{array}$} & Vessels priority rate. & 0 of 1.0 \\
\hline & & Barge priority rate. & 0.5 of 1.0 \\
\hline & & Number of barges at time zero. & 10 \\
\hline & & Number of vessels at time zero. & 0 \\
\hline & & Terminal efficiency. & 0.8 of 10 \\
\hline & & Crane performance. & 35 moves per hour \\
\hline & & Number of cranes & 3 \\
\hline \multirow{7}{*}{4} & \multirow{7}{*}{$\begin{array}{l}\text { Case 2: Dedicated Space } \\
\text { and Infrastructure for } \\
\text { Barges }\end{array}$} & Vessel priority rate. & 0 of 1.0 \\
\hline & & Barge priority rate. & 0.5 of 1.0 \\
\hline & & Number of barges at time zero & 10 \\
\hline & & Number of vessels at time zero & 0 \\
\hline & & Terminal efficiency & 0.8 of 10 \\
\hline & & Crane performance & 35 moves per hour \\
\hline & & Number of cranes & 4 \\
\hline
\end{tabular}

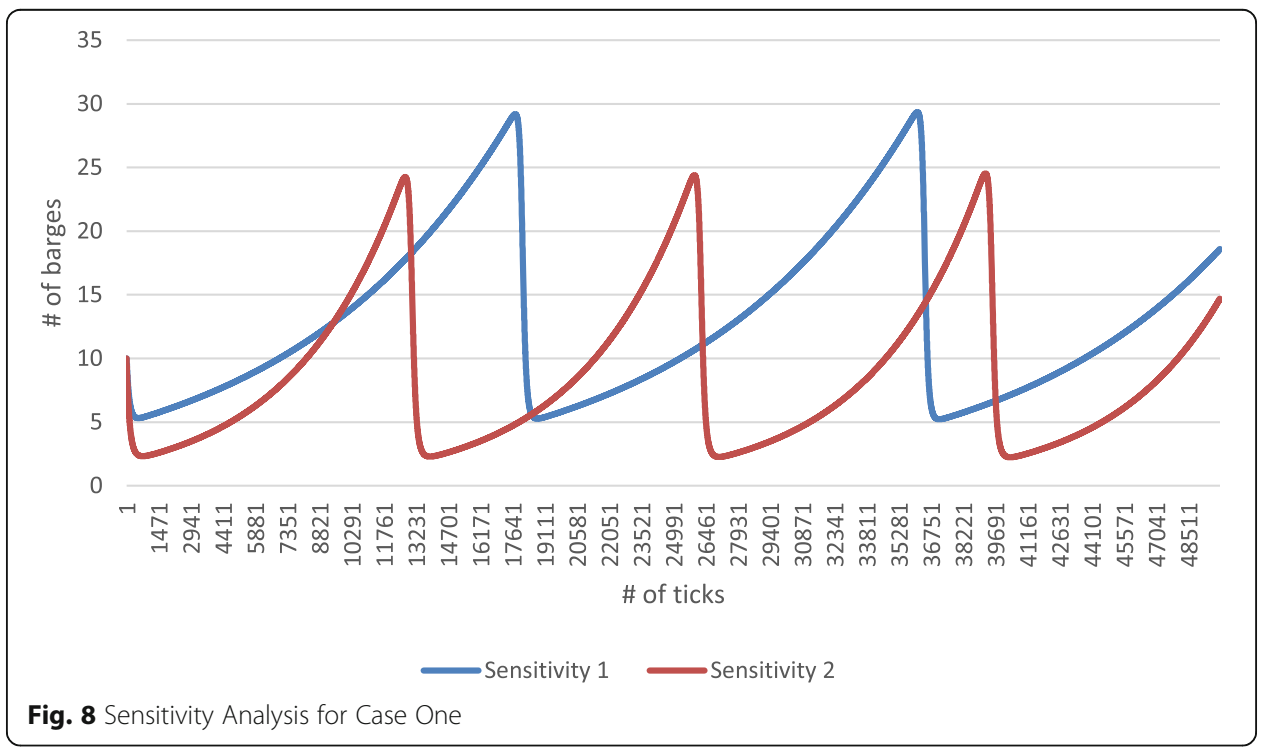


further lead to more build up and waiting time of barges at the terminals. Whereas, sensitivity analysis two for case one explains the situation if only the vessels priority rate was reduced to 0.8 (implying that there is an $80 \%$ chance that the vessel will be handled as soon as possible) while there was an increase of barges priority rate to 0.2 ( $20 \%$ chance of the barges being handled as soon as possible), while other parameters were held constant as in case one.

As can be seen, the maximum number of barges for sensitivity analysis one increased to 30 barges from the initial 10 at time step zero, while the minimum that would always be waiting to be handled at each of the time steps is five, while for sensitivity analysis 2 , the minimum number of barges waiting to be handled at any particular time step or ticks is reduced from 4 in the first situation to 3 in the current situation. There is however an increase in the maximum number of barges at any time step from 18 in the first situation to 25 barges in the current situation.

As can be seen from Fig. 8 above, an increase in either the priority rate of barges or the number of cranes at the terminal does not solve resolve the barge congestion problem if the barges and the deep-sea vessels still share the same terminal space for loading and unloading, instead the situation become worse (25 and 30 barges) as compared to the initial situation in the first case (18 barges). This is because deep-sea vessels will always be given high level of priority at the different terminals due to the agreements that they have with the deep-sea terminals, hence, an increase in the number of cranes, as well as an increase in the barge priority without dedicated space, will not be an optimal solution for the reduction of barge congestion in the terminals. Increasing barge priority while maintaining the priority level of the deep-sea vessels and without creating dedicated space for the barges will lead to more barges calling at the terminal which will subsequently lead to a further increase in congestion level.

In Fig. 9 the result of the sensitivity analysis of the second case is given. In this figure, the impact of changing the number of container cranes are researched.

Comparing the two sensitivity analyses of case two with the initial case two, the difference can clearly be seen in Fig. 9. The blue line represents the number of barges

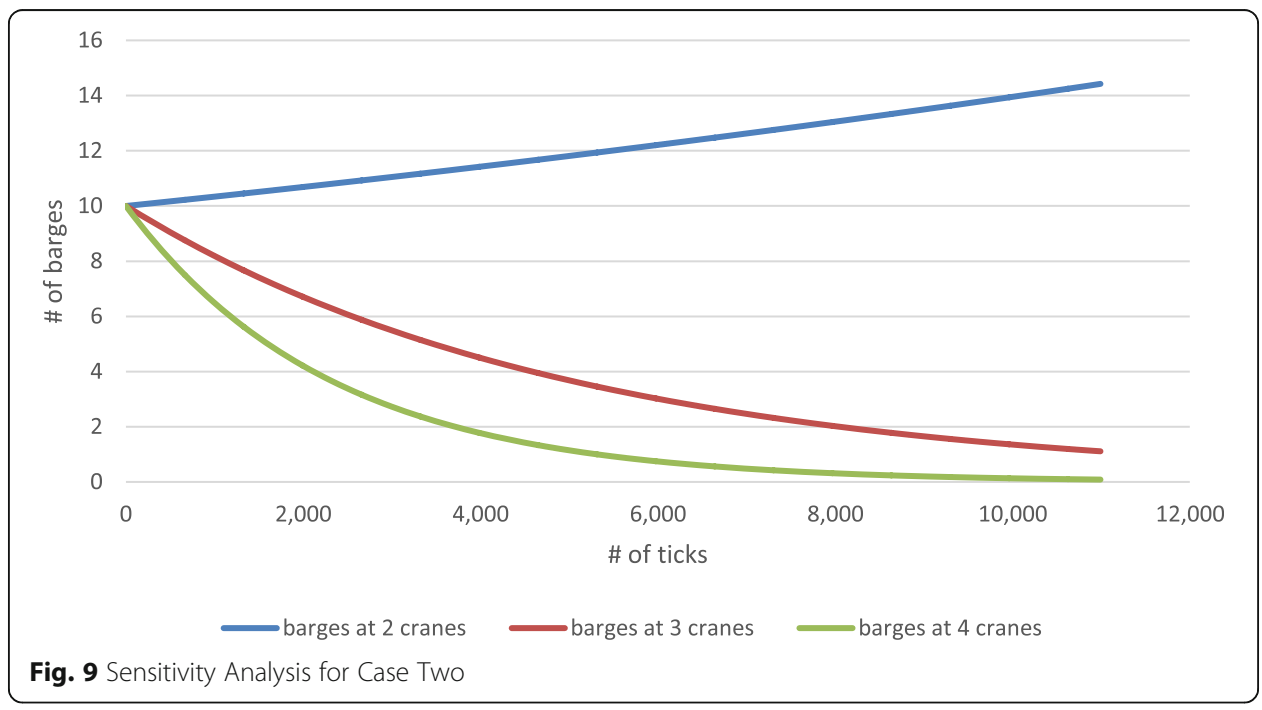


with two cranes invested in, the red line shows the number of barges when the number of cranes is increased to three, while the green line explains the number of barges when the cranes are further increased to four.

Both sensitivity analyses revealed a reduction in the congestion level of barges over time, however, it can be argued that sensitivity analysis 4 would not produce further reduction. Thus, it can be said that investing in an extra crane would not lead to a further significant reduction of barges than that of sensitivity analysis 3 . This further investment cannot be justified for by the terminal operators in the model as it would be a waste of resources, hence, sensitivity analysis 3 can be said to be the best situation in reaching a consensus for both the terminal operators in investing in the appropriate cranes, and the barge operators in reducing time and congestion level significantly.

An extrapolation of the figures from the model to the average number of barges that are being handled revealed that an extra 333 barges could be additionally handled if the barges have a dedicated space at each terminal. This leads to an increase of barges to an average of 1706 barges that could be handled per month from the initial average number of 1373 per month.

Figure 10 revealed the estimated time increase/decrease for the different cases and the sensitivity analysis carried out in the model. As seen in the figure, case 1 which is the independent decision on capacity and availability with high priority level for the vessels would lead to an estimated average delay of $6 \mathrm{~h}$ for the barges, case 2 which has to do with dedicated space and infrastructures for barges with only 2 cranes would lead to further delay of estimated average of $10 \mathrm{~h}$, while case 3 which is the integrated planning without reducing the priority level of barges would further lead to an estimated average delay of up to $20 \mathrm{~h}$ at the terminal.

The sensitivity analysis performed for the model, however, revealed that sensitivity analysis 1 which has to do with the calibration of case 1 to increase the number of cranes to 30 reduced the average waiting time by $2 \mathrm{~h}$ (from $6 \mathrm{~h}$ in case 1 to $4 \mathrm{~h}$ in sensitivity analysis 1 ).

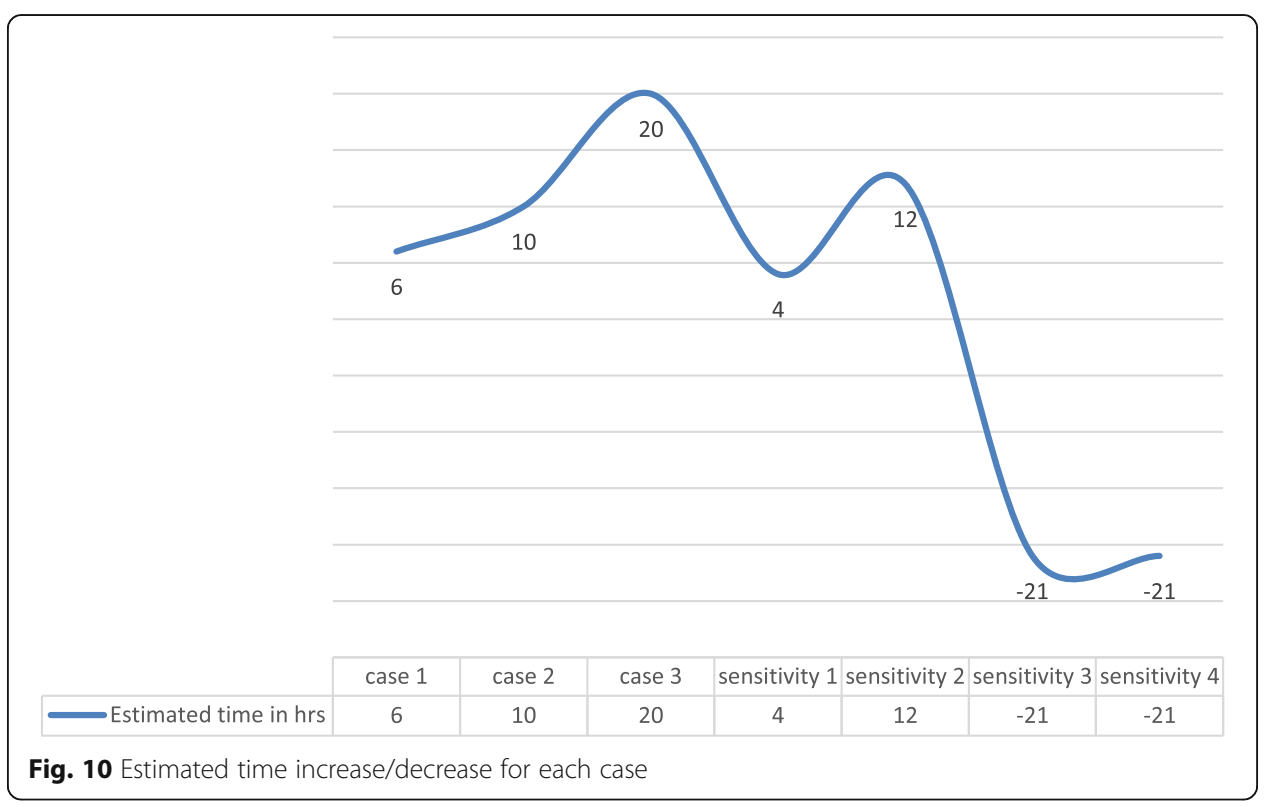


Sensitivity 2 is a calibration of case 3 with a slight increase in the barge priority rate and a slight decrease in the vessel priority rate while the number of cranes remains the same. The figure revealed that there is an increase in the waiting time by $2 \mathrm{~h}$ in this situation (from $10 \mathrm{~h}$ to $12 \mathrm{~h}$ ). A reason for this is because even though the priority rate was adjusted, the number of cranes remained constant and are majorly allocated to the vessels leading to further delay for the barges.

Sensitivity analysis 3 is a calibration case 2 in increasing the number of cranes from 2 to 3 totally dedicated only for the barges. As revealed in the figure, there is a significant reduction in the hours spent at each terminal with an estimated average reduction of $21 \mathrm{~h}$ for this approach. The same applies to sensitivity analysis 4 where the number of cranes is further calibrated to 4 .

The criteria for determining the best case is to examine the rate of reduction in the number of barges for each case, as well as the time reduction for each of the case. With this criterion, sensitivity 3 and 4 for case two are clearly the best situations. However, to select the best situation between the two-sensitivity analysis, the difference in time reduction and the rate of reduction of the barges must be discussed. The time reduction for both situations remains the same at $21 \mathrm{~h}$, furthermore, there is no significant reduction in the number of barges for sensitivity analysis 4 as compared to sensitivity analysis 3 . Thus, it can be said that investing in an extra crane would not lead to a further significant reduction of barges than that of sensitivity analysis 3 . This further investment cannot, therefore, be justified for by the terminal operators in the model as it would be a waste of resources, hence, it can be said that sensitivity analysis 3 is the best situation to reach a consensus for both the terminal operators in investing on the appropriate cranes, and the barge operators in reducing time and congestion level significantly.

The cases and sensitivity analysis in this model are focused on one terminal. This implies that the best case which is the dedicated barge space can be implemented at each terminal. Hence, it is suggested that for each terminal, there should be a dedicated barge space and an appropriate number of smaller cranes that should be dedicated for barge handling and operations.

A general phenomenon that can be deduced from this analysis is that the combination of the presence of vessels and the number of cranes allocated to the barges determine how long the barges would spend at each terminal. This implies that not only do the barges need dedicated spaces within each terminal, they also need the appropriate number of smaller cranes that is able to efficiently handle them at each terminal, otherwise the problem of congestion and handling would persist.

\section{Discussion and implication}

This paper examines the congestion of barges at deep-sea terminals in large seaports with hinterland connection. It examined a base case and two alternative scenarios to tackle the barge congestion in large seaports. The study identified several objectives which include: reduction of waiting time, enhancing barge handling, and improving barge reliability. With these objectives, the study provided answers to the research questions earlier identified. 
The first research question which seeks to examine why there is barge congestion in large seaports with strong IWT hinterland connection was answered by reviewing works of literature and discussing with researchers and industry practitioners involved in terminal and barge operation. The main identified reason for congestion from the different discussions revealed is the contractual agreement which sea vessels have with the deep-sea terminals which makes the terminals give them more priority over barges.

In this sense, the major contributor to barge congestion and poor handling at the port and deep-sea terminals are the behaviour of terminal operators towards focusing more on sea vessels due to the contractual relationship and influence that they have on them while neglecting the investments in barge infrastructures. Some carriers even acquire some terminals to have more control over how their vessels are handled and which gives the vessels even higher priority. Barges, however, are less expensive and are operated as a family business in most cases, hence most barge owners do not have the power to influence the terminals in giving them more priority. In this case, what the barge owners can only do is to wait till they are attended to which invariably leads to longer waiting time and a huge queue of barges.

The second research question which examines how congestion and waiting time of barges can be reduced in large seaports was answered by developing three scenarios. A system dynamic agent-based modelling was developed to examine the three scenarios and determine the optimum scenario to reduce congestion.

It was revealed by performed analysis that the case with dedicated barge space offers the best solution to the congestion issues. In this sense, if the terminals can create a dedicated handling space and invest in the right infrastructures for the barges, it could significantly reduce the waiting time of the barges and ensure that they do not spend a long period of time at the terminals. With this, there could be a shorter lead time leading to more reliability and the optimization of the supply chain flows. From the analyses can also be concluded that if barges get more attention, as they are given higher priority, the more barges will be attracted to the terminal. This will lead to an influx of barges at the terminal resulting in even more congestion.

\section{Conclusion and future research}

Investing in dedicated barge handling infrastructure has been found as the most promising option to reduce barge congestion. There is however concern about who would bear the responsibility of these investments and what the cost-benefit analysis of these investments would be. Therefore, more research is needed for this aspect. This further research should include:

What will be the cost for the terminal operators to invest in these additional crane capacities for barges, and what would be the benefits for terminal operators? Why should the deep-sea terminals invest in it if they see the barges as being less contributing to their productivity and throughput while the barge operators are the ones who benefit more? What role can the barge operators play to improve the situation, can they be more flexible by bundling and consolidating towards increasing the call size so there would be a reduced number of barges calling at different terminals? What is the implication of these moves? 
Further questions to be addressed include: what are the overall benefits for the general stakeholders which include the society? Is the overall cost-benefit analysis of the investment positive for the stakeholders, and if so, how do we compensate the stakeholders that incur the cost? What is the overall impact of the investments on freight modal shift, logistical flow and overall supply chain process?

More so, there have been discussions between terminal operators and barge operators on the minimum call size to be loaded on the barge before they can be handled at the terminals. It has been claimed by barge operators that smaller barges tend to have shorter waiting time than the bigger barges because the terminal operators can handle these barges between the vessels as soon as possible, hence the bigger barges must wait until the vessels take care of.

This has led to issues related to economies of scale as smaller barges can only transport a limited number of containers making it impossible to maximize the potential of inland water transportation in transporting larger quantities. Terminal operators, on the other hand, insist on the minimum call size of 30 containers for barges before they can be handled, and the minimum size does not even guarantee that they would be handled as soon as they call at the terminals.

Hence, there have been arguments from both parties looking to best represent their interests in reducing waiting time from the barge operators' point of view and optimizing capacity from the terminal operators' point of view. Thus, it would be interesting to examine how the different sizes of barge affect the congestion level at the terminals and the implication of the different size on economies of scale and transportation cost.

Finally, from the modelling point of view, it might be interesting to add more dynamics to the model in terms of the different vessel and barge size, peak and off-peak period and economic situation. It should also be noted that the call size of the barges is assumed to be the same and an average number of 30 TEUs were considered for all the barges. It would be interesting for future research to consider the different call sizes of barges, different TEUs for the barges and vessels and the different handing time in respect to the sizes and TEUs.

It might also be interesting to examine the congestion pattern to identify the specific period and days that have high congestion level as compared to days with a low level of congestion. Conclusively, it might be interesting to examine the overall cost implication of the different elements in relation to congestion level (smaller vs bigger vessels, congestion days, terminal call sizes, bundling and consolidation).

All these concerns need to be addressed to improve the situation of barges in large seaports. Hence, it is important that future research tend to proffer answers to these questions and discussions.

\section{Endnotes}

${ }^{1}$ MPET is a container terminal at the port of Antwerp

${ }^{2}$ Ticks represent the time steps in the netlogo model 


\section{Acknowledgements}

The authors want to thank Dennie Lockefeer for the insights he provided during the research and to arrange meetings with the container terminal operators in the port of Antwerp.

\section{Funding}

Not applicable.

\section{Availability of data and materials}

The data used in this paper was collected via interviews.

\section{Authors' contributions}

PS performed the literature review, did the interviews and built the model and performed the analysis. EvH has supervised the work PS and contributed by adding literature, provided input for the development of the model and suggested the sensitivity analysis in the paper. He also supported PS with the interpretation of the results and he helped in structuring the paper. Both authors read and approved the final manuscript.

\section{Competing interests}

The authors declare that they have no competing interests.

\section{Publisher's Note}

Springer Nature remains neutral with regard to jurisdictional claims in published maps and institutional affiliations.

Received: 19 December 2018 Accepted: 8 May 2019

Published online: 26 June 2019

\section{References}

Al Enezy O, Van Hassel E, Sys C, Vanelslander T (2017) Developing a cost calculation model for inland navigation. Research in Transportation Business and Management. https://doi.org/10.1016/.rtbm.2017.02.006

Baindur D, Viegas JM (2011) An agent-based model concept for assessing modal share in inter-regional freight transport markets. J Transp Geogr 19:1093-1105

Bonabeau E (2002) Agent-based modelling: methods and techniques for simulating human systems. Proc Natl Acad Sci U S A 99(Suppl. 3):7280-7287

Caris A, Macharis C, Janssens GK (2011) Network analysis of container barge transport in the port of Antwerp by means of simulation. J Transp Geogr 19(1):125-133

De Langen PW, Chouly A (2004) Hinterland access regimes in seaports. Eur J Transp Infrastruct Res 4(4):361-380

Douma A, Schurr P, Jagerman R (2011a) Degrees of terminal cooperativeness and the efficiency of the barge handling process. Expert Syst Appl 38(4):3580-3589

Douma A, Schurr P, Schutten J (2011 b) Aligning barge and terminal operations using service time profiles. Flex Serv Manuf J 23(4):385-421

Douma A, Schutten J, Schuur P (2009) Waiting profiles: an efficient protocol for enabling distributed planning of container barge rotations along terminals in the port of Rotterdam. Transp Res C 17(2):133-148

Eurostat (2018) Container transport by type of good (from 2007 onwards with NST2007) available at: http://appsso.eurostat. ec.europa.eu/nui/show.do?dataset=iww_go_actygo\&lang=en

Fan L, Wilson WW, Dahl B (2012) Congestion, port expansion and spatial competition for US container imports. Transport Res E-Log 48(6):1121-1136

Fischer K, Kuhn N, Müller HJ, Müller JP, Pischel M (1995) Sophisticated and distributed: the transportation domain - exploring emergent functionality in a real-world application. In: Castelfranchi C, Müller J-P (eds) From reaction to cognition. Springer, Berlin, pp 122-138

Fu Q, Liu L, Xu Z (2010) Port resources rationalization for better container barge services in Hong Kong. Marit Policy Manag 37(6):543-561

Huang Y-F, Hu J-K, Yang B (2015) Liner services network design and fleet deployment with empty container repositioning Comput Ind Eng 89:116-124

Konings R (2007) Opportunities to improve container barge handling in the port of Rotterdam from a transport network perspective. J Transp Geogr 15(6):443-454

Konings R, Kreutzberger E, Maras V (2013) Major considerations in developing a hub-and-spoke network to improve the cost performance of container barge transport in the hinterland: the case of the port of Rotterdam. J Transp Geogr 29:63-73

Li S, Negenborn R, Lodewijks G (2017a) Closed-loop coordination of inland vessels operations in large seaports using hybrid logic-based benders decomposition. Transp Res E 97:1-21

Li S, Negenborn R, Lodewijks G (2017b) Planning inland vessel operations in large seaports using a two-phase approach. Comput Ind Eng 106:41-57

Nextlogic, (2012). Chain optimization in container barging. <http://www.nextlogic.nl/>

North MJ, Macal CM (2007) Managing business complexity: discovering strategic solutions with agent-based modeling and simulation. Oxford University Press, Oxford

Oganesian, V., (2016). The impact of container barging (un) reliability in seaports on shippers: the case of the port of Antwerp. Master thesis C-MAT

Petering ME (2011) Decision support for yard capacity, fleet composition, truck substitutability, and scalability issues at seaport container terminals. Transport Res E-Log 47(1):85-103

Reis V (2010) Development of cargo business in the combination of airlines: strategy and instrument. Instituto Superio Técnico, University of Lisbon 
Reis V (2014) Analysis of mode choice variables in short-distance intermodal freight transport using an agent-based model in Transportation research part A: Policy and practice 61:100-120

Song DW, Panayides P (2012) Maritime logistics: a complete guide to effective shipping and port management. Kogan Page, Londen. ISBN 9780749463694

Van der Horst MR (2016) Coordination in Hinterland Chains: an institutional analysis of port-related transport. PhD Thesis, Delft University of Technology, Delft

Van der Horst MR, De Langen PW (2015) Port management. Palgrave Macmillan UK, London, Ch. Coordination in hinterland transport chains: a major challenge for the seaport community, pp 57-83

Van der Horst MR, Kuipers B (2013) A multidisciplinary analysis behind coordination problems in container barging in the port of Rotterdam, paper presented at International Association of Maritime Economists conference, 3-5 July, Marseille, France.

Visser J, Konings R, Pielage BJ, Wiegmans B (2007) A new hinterland transport concept for the port of Rotterdam: organizational and/or technological challenges? In: Paper presented at the 48th transportation research, forum. March, Boston, pp 15-17

Wilensky, U. (1999) NetLogo. Center for Connected Learning and Computer-Based Modeling, Northwestern University, Evanston, IL. http://ccl.northwestern.edu/netlogo/.

Submit your manuscript to a SpringerOpen ${ }^{\circ}$ journal and benefit from:

- Convenient online submission

- Rigorous peer review

- Open access: articles freely available online

High visibility within the field

- Retaining the copyright to your article

Submit your next manuscript at $\boldsymbol{\nabla}$ springeropen.com 